\title{
Genetics in the 21st Century: Implications for patients,
}

\section{consumers and citizens [version 1; peer review: 2 approved, 2}

\section{approved with reservations]}

\author{
Jonathan Roberts (iD, Anna Middleton (1)
}

Society and Ethics Research Group, Connecting Science, Cambridge, CB10 1SA, UK

V1 First published: 17 Nov 2017, 6:2020

https://doi.org/10.12688/f1000research.12850.1

Latest published: 24 Jan 2018, 6:2020

https://doi.org/10.12688/f1000research.12850.2

\section{Abstract}

The first human genome project, completed in 2003, uncovered the genetic building blocks of humankind. Painstakingly cataloguing the basic constituents of our DNA ('genome sequencing') took ten years, over three billion dollars and was a multinational collaboration. Since then, our ability to sequence genomes has been finessed so much that by 2017 it is possible to explore the 20,000 or so human genes for under $£ 1000$, in a matter of days. Such testing offers clues to our past, present and future health, as well as information about how we respond to medications so that truly 'personalised medicine' is now a reality.

The impact of such a 'genomic era' is likely to have some level of impact on all of us, even if we are not directly using healthcare services ourselves. We explore how advancements in genetics are likely to be experienced by people, as patients, consumers and citizens; and urge policy makers to take stock of the pervasive nature of the technology as well as the human response to it.

\section{Keywords}

genomics, patient, citizen, consumer

\section{Open Peer Review \\ Approval Status

$\begin{array}{llll}1 & 2 & 3 & 4\end{array}$ \\ version 2 \\ (revision) \\ $24 \operatorname{Jan} 2018$ \\ version 1 \\ 17 Nov 2017}

1. Anna Michell ID, University of Oxford, John Radcliffe Hospital, Oxford, UK

2. Lorraine Cowley (D), Newcastle University, Newcastle upon Tyne, UK

3. Michael Arribas-Ayllon, Cardiff University,

Cardiff, UK

4. Tina-Marie Wessels (iD, University of Cape

Town, Cape Town, South Africa

Any reports and responses or comments on the article can be found at the end of the article. 
Corresponding author: Jonathan Roberts (jr23@sanger.ac.uk)

Author roles: Roberts J: Writing - Original Draft Preparation, Writing - Review \& Editing; Middleton A: Writing - Review \& Editing Competing interests: No competing interests were disclosed.

Grant information: Anna Middleton and Jonathan Roberts are supported by the Wellcome Trust [206194]. Jonathan Roberts is funded by the Rosalind Driver Scholarship fund (King's College London) and by funding from the Public Engagement team at Connecting Science, Wellcome Genome Campus.

The funders had no role in study design, data collection and analysis, decision to publish, or preparation of the manuscript.

Copyright: ( 2017 Roberts J and Middleton A. This is an open access article distributed under the terms of the Creative Commons Attribution License, which permits unrestricted use, distribution, and reproduction in any medium, provided the original work is properly cited.

How to cite this article: Roberts J and Middleton A. Genetics in the 21st Century: Implications for patients, consumers and citizens [version 1; peer review: 2 approved, 2 approved with reservations] F1000Research 2017, 6:2020

https://doi.org/10.12688/f1000research.12850.1

First published: 17 Nov 2017, 6:2020 https://doi.org/10.12688/f1000research.12850.1 


\section{Introduction}

Genomic technology is now being utilised in more settings across society than ever before, including medicine, population health screening, recreational consumerism (ancestry testing, nutritional testing), through to policing and crime prevention. Signifying the importance placed on genomics, the most recent annual report of the Chief Medical Officer of the United Kingdom (2017) was entitled "Generation Genome" and stated:

"Genomics is not tomorrow. It's here today. I believe genomic services should be available to more patients, whilst being a cost-effective service in the NHS. This is exciting science with the potential for fantastic improvements in prevention, health protection and patient outcomes. Now we need to welcome the genomic era and deliver the genomic dream!"1

As members of the public we are all likely to all be exposed to some level of genomics within our lifetime - whether it be directly via a medical test, indirectly through marketing for recreational testing or distantly through being biologically related to someone whose DNA is contained within a national database. Given that genomic information links us to our relatives, the decisions that we make about it (whether to donate it for research, whether to be tested, whether to withhold it) will all have an impact on those we are related to and the knowledge that they too can gain. It is this fact that makes genetic information quite different from other sorts of medical information. Thus, we all have a stake in policy that guides the utilisation of genomic data. Within this opinion article, we reflect upon some of the ways that genomic data may touch us as patients, consumers and citizens.

\section{People as patients}

The UK has been an early implementer of genomics in a healthcare setting. In 2014, the Deciphering Developmental Disorders Study reported the first results from the sequencing of 12,000 children with developmental disorders ${ }^{2}$. At the same time, work began on a project to sequence 100,000 genomes of 70,000 NHS patients ${ }^{3}$. Outside of the UK, sequencing in healthcare settings is also expanding. For example, the National Institutes of Health Precision Medicine Initiative in the US offers 1 million people some level of genomic sequencing ${ }^{4}$ and the Australian Genomics Health Alliance is currently creating the infrastructure to integrate genomic medicine into healthcare nationally. Possibly the most striking example comes form Qatar where the government has plans to offer genome sequencing to their entire population (www.qatargenome.org.qa/). Thus we can see that genomic technology is now being utilised globally in a wide range of contexts to provide diagnostic, prognostic and treatment information for patients using healthcare services in a way that is predicted to transform healthcare ${ }^{1}$.

Genetic testing is currently used in a wide range of healthcare settings, including the diagnosis of rare disease in paediatrics, prenatal care, ophthalmology, dermatology, ENT, etc. Such testing will continue to be used in these settings. However, as genetic testing (single genes) shifts to genomic testing (many genes) and the ability to test becomes faster and cheaper, a key change that will occur is a dramatic increase in the amount of information generated.
As an example, as recently as 5 years ago, a breast cancer patient who also has family history of young onset breast cancer would likely be tested in a healthcare setting for two genes (BRCA1 and BRCA2). Mutations in these genes are known to lead an increased risk for certain types of cancer, most notably breast and ovarian cancer. Whereas now, such a patient may have a 'panel test' where over 20 genes associated with breast cancer are explored ${ }^{5}$. Each of these genes will have different links to cancer, thus increasing the complexity of the results that emerge. In addition to using genomic technology to understand the genetic basis of an existing condition such as breast cancer, it can also be used to uncover a new diagnosis for a previously undescribed rare condition ${ }^{6}$. Again, here the key change is the volume of information that will be generated. Instead of testing just a few genes, a child with an unknown developmental disorder may now have 20,000+ genes sequenced and then filtered bioinformatically to explore all of the genes linked to intellectual disability, autism and developmental conditions. This may reveal new diagnostic or prognostic information. Whilst it is unrealistic to suggest that all 20,000 genes will be analysed and reported as a whole $^{7}$, the resource is at least available to be interrogated as and when required. Genomic medicine is now available across whole healthcare systems, it has been truly 'mainstreamed' ${ }^{6,8}$. Thus, patients have more exposure than ever before to the volume and complexity of genetic information.

An increase in the scale of testing available inevitably also means an increase in the range of results returned - many of which, in the current climate, can only be interpreted as ambiguous or uncertain (due to the embryonic nature of our knowledge of this field) ${ }^{9}$. Such 'Variants of Unknown Significance' are results where the meaning is unclear and are more likely to be discovered when multiple genes are tested for at once ${ }^{10}$. In addition to the management of uncertainty, patients will be faced with more information options and so it becomes ever more pertinent to ask 'how much do you really want to know? ${ }^{11}$. Given the ability to look at multiple genes within one test, genomic technologies deliver an opportunity to serendipitously explore genes unrelated to the health condition being explored. This means that when a patient has their cancer genes looked at it would also be possible, at the same time, to explore their genes linked to heart disease. Such results might be referred to as 'additional looked for findings' ${ }^{3}$, 'secondary or incidental findings' or an 'opportunistic screen' ${ }^{11}$. Indeed, within the NHS's 100,000 Genomes Project parents of a child who is having genome sequencing can have the opportunity to be tested for 'additional looked for findings' related to their own risk of future disease, unrelated to their child's condition ${ }^{12}$.

Genomic testing is also increasingly being used to guide treatment options and provide more individualised risk assessments, often called 'precision' or 'personalised' medicine ${ }^{13}$. This allows clinicians and genetic counsellors to explore predispositions to developing future disease, thereby enabling steps for prevention, screening and/or management to be taken. Furthermore, this is linked to pharmacogenomics - genetic testing used to guide drug use in medicine. For example, before prescribing, patients may be tested first to see if they are likely to be able to metabolise certain drugs ${ }^{14}$. This is also being used in oncology, where chemotherapies are targeted towards a people with certain genetic profiles ${ }^{15}$. 
Genomic information is different to other sorts of medical information, in that it is shared between biological relatives. So, even if a person is not using healthcare services themselves, they may be related to someone else who is; thus, the reach of the results moves outside of the clinical encounter and into the wider family. Whilst most of us will not currently be a patient in a healthcare setting, we may still be related to someone who is having testing and the questions they have answered may be very relevant to us too. Therefore, the impact of genomic information naturally extends beyond a healthcare encounter-through conversation it travels from the patient, out to their extended family and to people who are not yet patients. Such people could be considered a type of "patient in waiting ${ }^{16}$; we don't yet know where and how they seek out information and meaning, but it is likely they look to the media ${ }^{17}$, popular culture $^{18}$ and the Internet ${ }^{19}$ for insight.

The complex ways that genetics - and now genomics - will affect patients, means that the provision of genetic counselling is of increasing in significance. Patients have voiced the opinion that the provision of genetic counselling is important when having genome sequencing ${ }^{20}$. Researchers and clinicians have also highlighted the importance of drawing on the expertise of genetic counsellors in order to ensure new technologies are integrated appropriately into healthcare ${ }^{21}$.

\section{People as consumers}

Having discussed some of the implications of genetics for patients we will now explore some of the ways that genomics will affect people as 'consumers.' One way is via 'direct to consumer' (DTC) genetic testing. This is a growing industry with private companies marketing and selling a wide range of tests through the Internet. Consumers are able to send off a DNA sample (normally a saliva sample) and a few weeks later receive their test results. There are a wide range of DTC genetic tests both health related and non-health related. Health related tests include identifying predispositions to common and complex disorders, such as cancer and cardiovascular disease, tests for carrier status that could guide reproductive decisions, and nutrigenomics and pharmacogenomics that could potentially guide treatment and lifestyle choices ${ }^{22}$. Non health-related tests include testing for paternity, ancestry, athletic ability, as well as traits such as earwax characteristics and caffeine metabolism ${ }^{22}$. DTC genetic testing is rising in prominence. In 2008, 23andMe's retail DNA testing kit was named invention of the year by Time magazine. In 2016, genomics was named by Forbes as one of the three 'Big Technologies to Watch' over the subsequent decade, together with nanotechnology and robotics, predicted to have the biggest impact on society ${ }^{23}$.

The potential risks and benefits of DTC genetic testing have been widely debated. Proponents argue that they empower consumers to take responsibility for their health ${ }^{24}$ and improve the quality of their life $^{25}$. However, researchers and health professionals have raised concerns about the clinical validity of DTC genetic tests, particularly in relation to susceptibility testing for complex disease, such as diabetes or dementia ${ }^{26,27}$. Specifically, researchers have argued that these tests fail to take into account non-genetic factors that can contribute to complex disease ${ }^{24}$. For Mendelian conditions, where a single gene is causative of disease, concerns have been voiced regarding the negative and positive predictive value of DTC genetics tests ${ }^{28}$. Researchers have also expressed concerns that when testing for serious, potentially life-threatening conditions, there is the possibility for unanticipated emotional reactions that cannot easily be addressed immediately via an Internet based service ${ }^{29}$. Despite the professional bodies who represent genetic health professionals (e.g. European Society Human Genetics and American College of Medical Genetics and Genomics) recommending that genetic counselling should be provided by DTC genetic testing companies, a review of such services indicated that the support services on offer are often severely lacking ${ }^{30}$.

DTC genetic testing is a growth market and as genetic testing becomes cheaper an increasing number of online genetic services will be available to members of the public ${ }^{31}$. With purported plans to incorporate genomic testing into the Apple watch ${ }^{32}$, as well as fitness monitoring market ${ }^{33}$, we as consumers will be faced with more opportunities to engage with genomic technology and the implications for our health and wellbeing.

In making purchasing decisions consumers will increasingly have to draw on their scientific understanding as well as cultural beliefs in order to make purchasing decisions. Abrams and colleagues conclude:

"Such exposure to genomics information outside of the clinical setting call upon the public to independently evaluate the veracity of these claims and make related decisions" 34 .

\section{People as citizens}

So far, we have explored the implications of genetics for us as patients and consumers. Finally, by focussing on some of the novel ethical dilemmas that will arise from technological advancements, we are able to explore some of the broader societal implications of genomics for us as citizens.

Scholars have drawn attention to the ways in which commercial companies are exploiting new genomic technologies ${ }^{35}$ with genomic and post-genomic (e.g. stem-cell) science seen as a crucial aspect of many state economic strategies ${ }^{36}$. Indeed one of the primary functions of the 100,000 Genomes Project, the NHS genomic sequencing project, is: "Stimulating and enhancing UK industry and investment" $"$.

The commercialisation of genomics is inevitable; indeed, to accelerate future drug development, it is imperative. However, with the for-profit industry comes an ethical tension in relation to the raw assets - genomes - that form the resource of data used in genomic research. Empirical research has shown us that whilst publics are willing to donate their DNA and medical information for use in research, they are more suspicious of donating their data for use by for-profit companies ${ }^{37}$; with concerns that unaffordable medicines would be developed as well as profits made for shareholders that they would not benefit from. We are encouraged as citizens to be altruistic with the donation of our data for the greater good and yet at the same time many will benefit, in a monetary sense, from this altruism. This tension is subject to increasing debate ${ }^{38,39}$. 
Genomic data is commonly stored electronically online; it is exchanged, shared and traded over the Internet every second of the day, as clinicians and researchers and pharmaceutical companies alike explore what a specific variant means. In order to interpret the significance of an individual finding, researchers need to see how this finding has expressed itself previously, by comparing it to datasets from thousands of other people ${ }^{30}$. The importance of sharing data is outlined by Lucassen and Montgomery (2017) who say:

"Genomics offers benefits and responsibilities for the individual, the family, the broader community and globally that cannot be realized by keeping the secrets revealed from one genome separate from others." ${ }^{40}(\mathrm{Ch} 16, \mathrm{p} 4)$

Thus, for us as citizens there are now emerging ethical dilemmas in relation to data security and privacy. If the only way to fully realise the potential of genomics is to collect large volumes of genomic data from millions of people (to be accessed by clinicians, nonprofit and for-profit researchers in the endeavour to better understand the link between genes and disease), then this means that such data needs to be stored online, shared, and protected against unauthorised use. Together with medical data, the storage of DNA information forms one of the key issues for international policy creation - with the pivotal issue being how to make online data storage safe and secure ${ }^{41}$.

One very significant dataset of genomic information is contained within the UK's National DNA Database. Here, DNA information is stored from people who are convicted, cautioned or recently arrested of a crime and can be matched to DNA collected from crime scenes. Scholars have raised concerns about how DNA should be utilised in criminal law, with DNA databases having a disproportionally high number of people of ethnic minority status ${ }^{42}$. It was this fact that Lord Justice Stephen Sedley used when arguing for expansion of the National DNA Database. Sedley countered civil liberty concerns arguing that a universal database would be less discriminatory if it was representative of the national population ${ }^{42}$.

Concerns about discrimination have also been raised in other policy areas regarding genetics. Scholars writing from a disability rights perspective have argued that genetic screening programs can reify a view of disability as purely a medical issue, ignoring social barriers that marginalise people in society. As such, implicit judgments are made about what is a worthwhile life, with genetic screening programmes having the potential to increase discrimination of people with disabilities ${ }^{43}$.

\section{Conclusions}

In this opinion article, we have charted some of the wide-ranging implications of advancements in genomics. The implications have been explored in relation to the experience people have in three contexts, as patients, consumers and citizens.
Given that genomic technology is here to stay and is increasing its foothold across the whole of society, we need to be mindful of taking stock and reviewing what sort of society we want to live in. There needs to be more psychosocial research to understand the attitudes, values and opinions people have about the use and application of genomics. Without this we are in danger of the technology being prescriptive of how society should function, instead of the other way around.

The societal implications of genomics include many facets. Within this article we provide a brief overview of the availability of genomic tests within medicine and the subsequent increase in engagement with uncertainty, the Direct to Consumer genetic testing market and commercialisation of genomics, the use of DNA databases by the police, the concerns about genomic screening programmes propagating discrimination and the necessity to ensure privacy and security of genomic data. These are all examples of the ways in which genetics/genomics will influence our lives as patients, consumers and citizens, and are all areas that are important for policy consolidation.

Genomic technology is now so pervasive across society and all of us, whether we see ourselves as a patient (or biologically related to a patient), a consumer or a citizen, we are likely to be confronted by the outcomes of genomics. Because of this there is an urgent need to explore the impact of the technology from many different societal perspectives. Together with normative bioethics, empirical data from people making sense of genomics should guide policy decision making so that the implementation of genomic technology is a positive endeavour that benefits humankind.

\section{Competing interests}

The authors declare no competing interests.

\section{Grant information}

Anna Middleton and Jonathan Roberts are supported by the Wellcome Trust [206194]. Jonathan Roberts is funded by the Rosalind Driver Scholarship fund (King's College London) and by funding from the Public Engagement team at Connecting Science, Wellcome Genome Campus.

The funders had no role in study design, data collection and analysis, decision to publish, or preparation of the manuscript.

\section{Acknowledgements}

We would like to acknowledge Dr Julia Willingale-Theune, Prof. Louise Archer and Dr. Jennifer DeWitt, Prof. Becky Francis and Prof. Justin Dillon for their support in the doctoral research that has influenced this opinion article. From the Wellcome Genome Campus we would also like to acknowledge the support of the public engagement team who have supported the doctoral research project and worked closely with the society and ethics team. 
1. Davies SC: Annual report of the chief medical officer 2016, generation genome. Department of Health. 2017; 1-256.

Reference Source

2. Wright CF, Fitzgerald TW, Jones WD, et al:: Genetic diagnosis of developmental disorders in the ddd study: a scalable analysis of genome-wide research data. Lancet. 2015; 385(9975): 1305-1314.

PubMed Abstract | Publisher Full Text | Free Full Text

3. Genomics England: The 100,000 genomes project 2017. 2017. Reference Source

4. Vaithinathan AG, Asokan V: Public health and precision medicine share a goal. J Evid Based Med. 2017; 10(2): 76-80.

PubMed Abstract | Publisher Full Text

5. Couch FJ, Shimelis H, Hu C, et al:: Associations Between Cancer Predisposition Testing Panel Genes and Breast Cancer. JAMA Oncol. 2017; 3(9): 1190-1196. PubMed Abstract | Publisher Full Text | Free Full Text

6. Kotze MJ, Lückhoff HK, Peeters AV, et al: Genomic medicine and risk prediction across the disease spectrum. Crit Rev Clin Lab Sci. 2015; 52(3): 120-137. PubMed Abstract | Publisher Full Text

7. Ormond KE, Wheeler MT, Hudgins L, et al.: Challenges in the clinical application of whole-genome sequencing. Lancet. 2010; 375(9727): 1749-1751. PubMed Abstract | Publisher Full Text

8. Brown TL, Meloche TM: Exome sequencing a review of new strategies for rare genomic disease research. Genomics. 2016; 108(3-4): 109-114. PubMed Abstract | Publisher Full Text

9. Slavin TP, Niell-Swiller M, Solomon I, et al:: Clinical Application of Multigene Panels: Challenges of Next-Generation Counseling and Cancer Risk Management. Front Oncol. 2015; 5: 208 PubMed Abstract | Publisher Full Text | Free Full Text

10. Petersen BS, Fredrich B, Hoeppner MP, et al:: Opportunities and challenges of whole-genome and -exome sequencing. BMC Genet. 2017; 18(1): 14. PubMed Abstract | Publisher Full Text | Free Full Text

11. Middleton A, Morley $\mathrm{KI}$, Bragin $\mathrm{E}$, et al.: Attitudes of nearly $\mathbf{7 0 0 0}$ health professionals, genomic researchers and publics toward the return of incidental results from sequencing research. Eur J Hum Genet. 2016; 24(1): $21-9$

PubMed Abstract | Publisher Full Text | Free Full Text

12. Caulfield M, Davies J, Dennys M, et al.: The 100,000 genomes project protocol. figshare. 2017. Publisher Full Text

13. Feiler T, Gaitskell K, Maughan T, et al:: Personalised Medicine: The Promise, the Hype and the Pitfalls. New Bioeth. 2017; 23(1): 1-12. PubMed Abstract | Publisher Full Text

14. Zineh I, Pacanowski M, Woodcock J: Pharmacogenetics and coumarin dosing-recalibrating expectations. N Engl J Med. 2013; 369(24): 2273-5. PubMed Abstract | Publisher Full Text

15. Schütte M, Ogilvie LA, Rieke DT, et al:: Cancer Precision Medicine: Why More Is More and DNA Is Not Enough. Public Health Genomics. 2017; 20(2): 70-80. PubMed Abstract | Publisher Full Text

16. Timmermans S, Buchbinder M: Patients-in-waiting: Living between sickness and health in the genomics era. J Health Soc Behav. 2010; 51(4): 408-423. PubMed Abstract | Publisher Full Text

17. Yoon H, Sohn M, Jung M: Media Use and the Cancer Communication Strategie of Cancer Survivors. J Cancer Prev. 2016; 21(3): 127-134. PubMed Abstract | Publisher Full Text | Free Full Text

18. Weinberger S, Greenbaum D: Genetic technology to prevent disabilities: How popular culture informs our understanding of the use of genetics to define and prevent undesirable traits. Am J Bioeth. 2015; 15(6): 32-34. PubMed Abstract | Publisher Full Text

19. Brown SN, Jouni H, Marroush TS, et al.: Effect of Disclosing Genetic Risk for Coronary Heart Disease on Information Seeking and Sharing:The MI-GENES Study (Myocardial Infarction Genes). Circ Cardiovasc Genet. 2017; 10(4): pii: e001613.

PubMed Abstract | Publisher Full Text | Free Full Text

20. Genetic Alliance UK: What do patients with rare genetic conditions think about whole genome sequencing in the nhs? research findings for the 100,000 genomes project. 2014

Reference Source

21. Middleton A, Hall G, Patch C: Genetic counselors and Genomic Counseling in the United Kingdom. Mol Genet Genomic Med. 2015; 3(2): 79-83. PubMed Abstract | Publisher Full Text | Free Full Text
22. Kalokairinou L, Howard HC, Borry P: Direct-to-consumer genetic testing. eLS. 2014 Publisher Full Text

23. Satell G: The $\mathbf{3}$ big technologies to watch over the next decade genomics, nanotechnology and robotics. Forbes Magazine. 2016. Reference Source

24. McGuire AL, Burke W: Health system implications of direct-to-consumer personal genome testing. Public Health Genomics. 2011; 14(1): 53-58. PubMed Abstract | Publisher Full Text | Free Full Text

25. Hogarth S: Myths, misconceptions and myopia: searching for clarity in the debate about the regulation of consumer genetics. Public Health Genomics. 2010; 13(5): 322-326.

PubMed Abstract | Publisher Full Text | Free Full Text

26. Covolo L, Rubinelli S, Ceretti E, et al:: Internet-Based Direct-to-Consumer Genetic Testing: A Systematic Review. J Med Internet Res. 2015; 17(12): e279. PubMed Abstract | Publisher Full Text | Free Full Text

27. Sturm AC, Manickam K: Direct-to-consumer personal genomic testing: a case study and practical recommendations for "genomic counseling". J Genet Couns. 2012; 21(3): 402-412.

PubMed Abstract | Publisher Full Text

28. Hunter DJ, Khoury MJ, Drazen JM: Letting the genome out of the bottle--will we get our wish? N Engl J Med. 2008; 358(2): 105-107. PubMed Abstract | Publisher Full Text

29. Middleton A, Mendes Á, Benjamin CM, et al.: Direct-to-consumer genetic testing: where and how does genetic counseling fit? Per Med. 2017; 14(3). Publisher Full Text

30. Middleton A: Your DNA, Your Say. New Bioeth. 2017; 23(1): 74-80. PubMed Abstract | Publisher Full Text | Free Full Text

31. Hall JA, Gertz R, Amato J, et al:: Transparency of genetic testing services for 'health, wellness and lifestyle': analysis of online prepurchase information for uk consumers. Eur J Hum Genet. 2017; 25(8): 908-917. PubMed Abstract | Publisher Full Text | Free Full Text

32. Regalado A: Apple has plans for your dna. MIT Technology reivew, 2015. Reference Source

33. Human K: Maximising your health data. Genome Mag. 2017. Reference Source

34. Abrams LR, McBride CM, Hooker GW, et al:: The many facets of genetic literacy: assessing the scalability of multiple measures for broad use in survey research. PLoS One. 2015; 10(10): e0141532.

PubMed Abstract | Publisher Full Text | Free Full Text

35. Rabinow P, Dan-Cohen T: A machine to make a future: Biotech chronicles. Princeton University Press, 2013 Reference Source

36. Lynch M, McNally R, Atkinson P, et al.: The Handbook of Genetics and Society: Mapping the New Genomic Era. Routledge, 2009. Reference Source

37. MORI Ipsos: The one-way mirror: Public attitudes to commercial access to health data. London: Wellcome Trust. 2016. Reference Source

38. Parker M, Bull S: Sharing Public Health Research Data: Toward the Development of Ethical Data-Sharing Practice in Low- and Middle-Income Settings. J Empir Res Hum Res Ethics. 2015; 10(3): 217-224. PubMed Abstract | Publisher Full Text | Free Full Text

39. Dove ES, Özdemir V: What role for law, human rights, and bioethics in an age of big data, consortia science, and consortia ethics? the importance of trustworthiness. Laws. 2015; 4(3): 515-540. PubMed Abstract | Publisher Full Text | Free Full Text

40. Lucassen A, Montgomery J, Parker M: Ethics and the social contract for genomics in the nhs. Annual Report of the Chief Medical Officer 2016. Departmen of Health Chapter 16, 2017.

Reference Source

41. Global Alliance for Genomics and Health: White paper: creating a global alliance to enable responsible sharing of genomic and clinical data. 2013. Reference Source

42. Lynch M, McNally R: Forensic dna databases and biolegality. Handbook of Genetics and Society. London: Routledge. 2009; 283-301. Reference Source

43. Shakespeare $\mathrm{T}$ : Choices and rights: eugenics, genetics and disability equality. Disability Society. 1998; 13(5): 665-681. PubMed Abstract | Publisher Full Text 


\section{Open Peer Review}

\section{Current Peer Review Status:}

\section{Version 1}

Reviewer Report 07 December 2017

https://doi.org/10.5256/f1000research.13925.r28119

(C) 2017 Wessels T. This is an open access peer review report distributed under the terms of the Creative Commons Attribution License, which permits unrestricted use, distribution, and reproduction in any medium, provided the original work is properly cited.

\section{Tina-Marie Wessels}

Division Human Genetics, University of Cape Town, Cape Town, South Africa

This opinion piece covers the pertinent issues we are currently grappling with as genomic medicine gains momentum. The authors highlighted the many facets and far-reaching consequences well.

The authors discussed how we have moved from single genes to panels (many genes) to whole exome and genome sequencing and the use of bioinformatics to identify relevant variants. An important issue is the different tools available in bioinformatics, how these are applied in specific cases and how these effect what is regarded as significant and what is not. This field is growing and it will continue to improve its algorithms so to increase the accuracy of variant calling. In addition, distinguishing between normal variation and pathogenicity is currently problematic when working with non-European populations. Concerted affords are underway to address the underrepresentation of diverse population (Ramesar $2015^{1}$ ).

The authors state that genetic counselling will be increasingly more significant. It is important to mention that the role of clinical genetics i.e. taking a comprehensive family history and using clinical information to guide and or assist with the interpretations of genomic data will remain important. Except for the traditional role of genetic counsellors helping consumers understand and make informed choices as pointed out, the role of genetic counsellors is expected to expand to include providing support to other healthcare providers involved with the ordering of genomic tests, assistance in developing online tools and education for both professionals and the public.

One aspect that requires more consideration in the genomics era is the need for education. The authors quote Abrams and colleagues that highlight the need for public education so that consumers can make informed decisions. Education for the public is essential but there is also a need for education of medical and other health care professionals as they will increasingly be involved in ordering and or interpreting genomic tests and use these results in the care of their patients. There are so many tests to choose from which makes it difficult to evaluate which have clinical utility. 
The authors highlighted the ethical dilemmas related to data security and privacy. Ethical dilemmas have been highlighted since the start of the human genome project (ELSI). The issues related to incidental findings and informed consent could be included in the article.

\section{References}

1. Ramesar R: Genomics: African dawn.Nature. 2015; 517 (7534): 276-7 PubMed Abstract |

Publisher Full Text

Is the topic of the opinion article discussed accurately in the context of the current literature?

Yes

Are all factual statements correct and adequately supported by citations?

Yes

Are arguments sufficiently supported by evidence from the published literature?

Yes

Are the conclusions drawn balanced and justified on the basis of the presented arguments? Yes

Competing Interests: No competing interests were disclosed.

Reviewer Expertise: Genetic counselling

I confirm that I have read this submission and believe that I have an appropriate level of expertise to confirm that it is of an acceptable scientific standard.

Reviewer Report 07 December 2017

https://doi.org/10.5256/f1000research.13925.r28116

(C) 2017 Arribas-Ayllon M. This is an open access peer review report distributed under the terms of the Creative Commons Attribution License, which permits unrestricted use, distribution, and reproduction in any medium, provided the original work is properly cited.

\section{Michael Arribas-Ayllon}

Cardiff School of Social Sciences, Cardiff University, Cardiff, UK

This is a clear and well-structured opinion piece that identifies many relevant issues concerning genetic and genomic testing and its presumed impact on society. I am unfamiliar with this journal, so I am unsure how to gauge the usefulness of this article for its readership.

My main concern is the extent to which the authors claim the pervasiveness of genomic technologies. In the sociological literature, with which I am more familiar, these claims are not all clear or straightforward. For instance, Adam Hedgecoe questions the utility of genetic testing, 
which can increase diagnostic uncertainty (also see Anne Kerr's work). He also argues that in the context of pharmacogenomics, genomic medicine in the clinic falls short of personalised medicine. Arribas-Ayllon (2016) reviews the literature to show that applications of genetic testing in healthcare are uneven and partial. Sophie Day et al. (2016) has also identified the ways in which genomic medicine further complicates treatment pathways for breast cancer. What is common to these and many other sociological studies is that genomic medicine consistently fall short of the hype that genetic and genomic technologies will be revolutionary and personalizing.

For instance, I am troubled by the frequent use of the pronoun 'all' in the first paragraph to suggest that genomic medicine is all-encompassing and totalising. It is not at all clear to me that genomic medicine is rolled out as smoothly and as evenly as the authors suggest. In fact, I wonder, given the age of austerity we now live under, whether these technologies will live up to the hype of delivering a 'truly' personalised medicine. I also wonder about the circumstances and sites in which this technology is not routinely available to everyone.

I am also troubled by the assertion made at the end of the third paragraph that genomic medicine 'has been truly 'mainstreamed". This is a strong statement. What confidence do the authors have that this is actually true? Of course, I think it serves the authors' argument to confidently state that genomic medicine has arrived and is here to stay because it justifies the urgent need to foster public dialogue about ethical and social implications regarding complex health information. But I feel the authors are overstating these claims. Again, sociological studies maintain that the roll-out of these technologies is not even nor does it not necessarily simplify or improve treatment pathways.

In so far as genomic medicine gives out complex and uncertain information, I think the author would benefit from reading the work of Joon-Ho et al. (2013) to elaborate the kinds of issues that arise when 'returning results' is framed in terms of a 'dynamic resource' of information that needs to be managed over the lifetime of an individual. This also has unique implications for genetic counselling.

Although I understand the authors are discussing genetics in general, the example of DTCGT is based on a different technology to that of the previous examples concerning whole genome sequencing. DTC companies use genotyping to calculate probabilistic risk for common complex disorders. I think the technical differences between sequencing and genotyping ought to be flagged. The general reader might reach the opinion that all genome testing is based on the same technologies.

In their Conclusion, the authors claim that there is a danger that genomic technology will be 'prescriptive of how society should function, instead of the other way around'. Firstly, I don't think this point has been sufficiently developed in the paper, or at least it doesn't follow naturally from the arguments and examples given above. I am also concerned that because the author are buying into the revolutionary hype of genomic medicine, that society is construed as being essentially passive.

\section{Recommendations}

I recommend that the authors tone down their claims that genomic medicine is revolutionary and pervasive.

I recommend the authors indicate that there are still significant obstacles of delivering 
personalised and stratified medicine in real-world settings.

I recommend that the authors explore more deeply the kind of relationship individuals can expect from sequence-driven information, especially in relation to how this information is likely to change over time (see Joon-Hu et al. $2013^{1}$ ).

\section{Minor revisions:}

On the last line of the second column on page 2 'where chemotherapies are targeted towards a people with...' should read 'where chemotherapies are targeted towards people with...'

On page 3, first column, in the second paragraph $2^{\text {nd }}$ line 'provision of genetic counselling is of increasing in significance' should read "provision of genetic counselling is of increasing significance'.

\section{References}

1. Yu JH, Jamal SM, Tabor HK, Bamshad MJ: Self-guided management of exome and whole-genome sequencing results: changing the results return model.Genet Med. 2013; 15 (9): 684-90 PubMed Abstract | Publisher Full Text

Is the topic of the opinion article discussed accurately in the context of the current literature?

Yes

Are all factual statements correct and adequately supported by citations? Yes

Are arguments sufficiently supported by evidence from the published literature? Partly

Are the conclusions drawn balanced and justified on the basis of the presented arguments? Partly

Competing Interests: No competing interests were disclosed.

Reviewer Expertise: Medical sociology and science and technology studies of genetic knowledge, esp. genetic testing

I confirm that I have read this submission and believe that I have an appropriate level of expertise to confirm that it is of an acceptable scientific standard, however I have significant reservations, as outlined above.

Author Response 18 Jan 2018

Jonathan Roberts, Connecting Science, Cambridge, UK

Thank you very much to Michael for his review. We have addressed his comments below (Reviewers comments are in italics)

This is a clear and well-structured opinion piece that identifies many relevant issues concerning 
genetic and genomic testing and its presumed impact on society.

Thank you.

I am unfamiliar with this journal, so I am unsure how to gauge the usefulness of this article for its readership.

We chose F1000 because we wanted a platform with good search engine optimisation, so that our article would be very easy to access and find (and thus not be limited by a single journal authorship group). The article has had 364 reads in a matter of weeks, so this bodes well in terms of reaching an interested audience. The paper was written as a broad, lighttouch opinion piece as opposed to addressing a specific issue for a particular audience, hence choosing a generic journal that covers all scientific disciplines. We also wrote it for a non-specialist, generic audience.

My main concern is the extent to which the authors claim the pervasiveness of genomic technologies.

There is absolutely no doubt that genomic technologies are here to stay and are embedded in many different settings. Our reference to the Chief Medical Officers report on Genomics provides evidence to the commitment to further embed genomic technology into healthcare services in the UK. We have also provided evidence (page 3, column 1, 'people as patients), outside of the UK where genomic technologies are being applied, on a large scale, for example in Australia, Qatar and the USA. In the interests of space we chose not to list the many other global sequencing initiatives, but for the reviewer's information, we could have added in details about the national sequencing initiatives in Pakistan, Switzerland, Canada, Turkey, Singapore, India, China, Japan and Latin America to name but a few countries to evidence the global reach of genomic technologies.

We also draw the reviewer's attention to the 'Million European Genomes Project', where genomic and health data will be linked from 1 million European patients: [Horgan D, Romao M, Hastings R. Pulling the Strands Together: MEGA Steps to Drive European Genomics and Personalised Medicine. Biomedicine Hub. 2017;2(suppl 1)481300 (DOI:10.1159/000481300)]. And also to the work of the Global Alliance for Genomics and Health (www.ga4gh.org) which represents more than 500 organisations worldwide all involved in genomic sequencing initiatives.

We have added some text about global utilisation of genomics: "A commitment to significant and ongoing investment in genomics on an international scale is demonstrated by the 'Million European Genomes Project', where genomic and health data will be linked from 1 million European patients and The Global Alliance for Genomics and Health ( www.ga4gh.org) that represents more than $500+$ organisations globally all with the shared endeavour of implementing and enabling genomic technology to be applied in research and clinical practice"

In the sociological literature, with which I am more familiar, these claims are not all clear or straightforward. For instance, Adam Hedgecoe questions the utility of genetic testing, which can 
increase diagnostic uncertainty (also see Anne Kerr's work).

Whilst it is true that the implementation of genomic medicine brings with it many uncertainties (and we have clearly alluded to some of these on page 3, second column, second para) we would contest that that genomic technology is pervasive and being delivered on a large scale.

He also argues that in the context of pharmacogenomics, genomic medicine in the clinic falls short of personalised medicine. Arribas-Ayllon (2016) reviews the literature to show that applications of genetic testing in healthcare are uneven and partial.

We are not in disagreement with the reviewer about the difficulties that genomic technologies bring and that the application across healthcare settings is uneven. Audiences could be guided to our other publications that offer more of a reflection of what is working and the difficulties, particularly for genetic counsellors, in the application of genomics in a healthcare setting, e.g. : Middleton A, Hall G, Patch C (2015) Genetic counsellors and Genomic Counselling in the United Kingdom. Molecular Genetics and Genomic Medicine 3(2) 79-83.)

Instead the purpose of the Opinion piece was to offer a non-specialist audience a summary piece on the different ways genomics will touch us as patients (or related to patients), citizens and consumers.

Sophie Day et al. (2016) has also identified the ways in which genomic medicine further complicates treatment pathways for breast cancer. What is common to these and many other sociological studies is that genomic medicine consistently fall short of the hype that genetic and genomic technologies will be revolutionary and personalizing.

We don't disagree with this. But it was not the aim of the Opinion Piece to offer a critique of these issues. Neither was it the aim of the Opinion Piece to provide copious examples of where genomic medicine is working incredibly well (of which there are many). However, it is important to ensure that this article acknowledges the implementation of genomics is complex. As such we have added the following text at page 3, column 1, paragraph 3

"While there are many ways in which genomics is improving healthcare, it is important to note that the implications of genomic medicine are multifaceted. For example Adam Hedgecoe (2008) questions the utility of genetic testing, which can increase diagnostic uncertainty and Sophie Day et al., (2017) has identified the ways in which genomic medicine further complicates treatment pathways for breast cancer. Arribas-Ayllon (2016) reviews the literature to show that applications of genetic testing in healthcare are uneven and partial."

For instance, I am troubled by the frequent use of the pronoun 'all' in the first paragraph to suggest that genomic medicine is all-encompassing and totalising. It is not at all clear to me that genomic medicine is rolled out as smoothly and as evenly as the authors suggest. In fact, I wonder, given the age of austerity we now live under, whether these technologies will live up to the hype of delivering a 'truly' personalised medicine. I also wonder about the circumstances and sites in which this technology is not routinely available to everyone. 
In response to the above comment we have 'toned down' some of the language. Specifically: In the abstract, paragraph 1, line 8: "'personalised medicine' is now a reality" now reads "'personalised medicine' is now moving closer to a reality."

In the abstract, paragraph 2, line 2: "The impact of such a 'genomic era' is likely to have some level of impact on all of us", now reads:

"The impact of such a 'genomic era' is likely to have some level of impact on an increasingly large number of us"

I am also troubled by the assertion made at the end of the third paragraph that genomic medicine 'has been truly 'mainstreamed". This is a strong statement. What confidence do the authors have that this is actually true?

In response to this comment some of the language has been changed. In page two, paragraph four, the penultimate sentence "Genomic medicine is now available across whole healthcare systems, it has been truly 'mainstreamed'" now reads:

"As genomic medicine is increasingly available across healthcare systems, we are moving closer to genetics becoming 'mainstreamed"'

While the author raises a valuable point regarding mainstreaming, it is undeniable that genetics is increasingly being used across a range of healthcare settings. For example at the time of writing this comment $(17 / 01 / 18)$ research has been published in the Journal of the National Cancer Institute that has provided evidence that BRCA testing for all women over the age of 30 is cost effective.

The Society and Ethics Research Group (where the authors are from) are part of the Wellcome Genome Campus in Cambridge, which in turn is a partner in the East of England Genomic Medicine Centre. Through teaching NHS members of staff, funded via Health Education England on the new MSc Genomic Medicine at the University of Cambridge, the authors are in contact with NHS staff involved in 'mainstreaming' genomics (i.e. applying new genomic knowledge to their practice). It is this experience that informs our knowledge of the way genomic technologies are influencing practice outside of specialist clinical genetics services. Thus we have confidence and experience in the statements we have made about genomics in a healthcare setting.

Of course, I think it serves the authors' argument to confidently state that genomic medicine has arrived and is here to stay because it justifies the urgent need to foster public dialogue about ethical and social implications regarding complex health information. But I feel the authors are overstating these claims. Again, sociological studies maintain that the roll-out of these technologies is not even nor does it not necessarily simplify or improve treatment pathways.

We do not believe the article implied that these technologies are simplified or have improved pathways in all situations. However, there is significant evidence that genomics has improved care in number of settings. Notably, in rare disease and the diagnosis of developmental delay, genomics has made it less likely that patients will have a long 'diagnostic odyssey'. Importantly for our purposes here, our argument is not based on genomics universally improving care. Rather that genomics will be increasingly used in 
healthcare settings. This may improve care (such as in rare disease) or may lead to increased uncertainty with a higher likelihood of finding and Variants of Uncertain significance. The key point is that dialogue needs to be fostered because genomics will have increasingly large applications in healthcare, a claim that is well supported through empirical evidence.

For examples of genomics improving care see the following reference for details of the cost effectiveness of sequencing in a clinical setting: Walsh et al (2017) The reviewer is also directed to the work of the Deciphering Developmental Disorders project that now has a diagnostic rate of more than $40 \%$, i.e. for children with severe developmental disorders who have not been able to receive a diagnosis for their condition via traditional NHS testing, more than $40 \%$ have received their diagnosis after exome sequencing. The DDD project also predicts that if whole exome sequencing was offered to these children as a first line test, more than 50\% would have received a diagnosis for their condition : Wright et al (2018)

In so far as genomic medicine gives out complex and uncertain information, I think the author would benefit from reading the work of Joon-Ho et al. (2013) to elaborate the kinds of issues that arise when 'returning results' is framed in terms of a 'dynamic resource' of information that needs to be managed over the lifetime of an individual. This also has unique implications for genetic counselling.

We did not want to engage in lengthy theoretical debate about the best ways complexity and uncertainty can be managed in clinical settings (this is a paper in itself!) We have already published our own empirical work $(n=7,000)$ on the return of results from sequencing studies [see Middleton et al 2016]. We are aware of Joon-Ho Yu et al's excellent work. However, as this is based on a theoretical approach that is not being applied within clinical settings we feel it is perhaps premature to offer this as a suggestion for how genomic medicine is working in practice now. However, the reviewer draws attention to an important debate. As such we have added the following text at page 3, column 1, penultimate paragraph. .

"As patients are exposed to increasingly complex and uncertain genetic information, debates have emerged as to the best way to manage this. Middleton et al., demonstrate that while many people are enthusiastic about receiving genetic information health professions (especially those who work in genetics) are more cautious. Joon-Ho et al., suggest that genetic information should be framed as a 'dynamic resource' with uncertainty managed by viewing this information as a resource that should be managed over the lifetime of an individual. There is as yet no consensus regarding the best way to manage the increasing volumes of complexity and uncertainty generated by genetic sequencing. In the ongoing debates we argue it is crucial that debates are informed by wide range of voices."

Although I understand the authors are discussing genetics in general, the example of DTCGT is based on a different technology to that of the previous examples concerning whole genome sequencing. DTC companies use genotyping to calculate probabilistic risk for common complex disorders. I think the technical differences between sequencing and genotyping ought to be 
flagged.

DCT also look for SNPs in genes that cause mendelian disease, the key issue here is their positive/negative predictive value.

The general reader might reach the opinion that all genome testing is based on the same technologies.

We understand the concern regarding the confusion of what could be called 'whole genome sequencing'. This term could refer to a wide range to technologies (micro-arrays, SNP arrays, whole exome sequence). We believe we have covered the key concerns of DTCGT in this section (clinical validity for information about common diseases and positive and negative predictive values for mendelian disease). We feel that additional information regarding the specific technologies would not add clarity. However, we have added a short explanation at the beginning on the paper clarifying how we are utilising the term 'whole genome' and that this references to a range of different technologies that provide different levels of information.

We have added the following text in at the beginning of the article (before "people as patients" section).

Before the continuing it is important to make clear that in this article we use the term 'genomic' to refer to a wide range of sequencing and laboratory technologies. There are a range of different technologies that interrogate the 'whole genome.' Next generation sequencing may be used to create a 'whole genome sequence' - a complete sequence all 3 billion base pairs of an individual's genome. However to generate a true whole genome sequence multiple sequencing methods (other than NGS) may need to be used. Furthermore there are a number of technologies that look across an entire genome but do not create a 'whole genome sequence' for example, microarrays, SNP arrays, and exome sequences. For our purposes we refer to all technologies that look across the genome as 'genomic'. Where there are specific technological issues (such as positive and negative predictive values in direct to consumer genetic tests) we refer to these. However, for clarity, we do not feel it it would be beneficial in this article to expand on the different technologies used for sequencing in different settings. As such for purposes of this article we discuss broadly the implications issues raised by 'genomic' technology with an understanding that this refers to a range of sequencing and testing techniques.

In their Conclusion, the authors claim that there is a danger that genomic technology will be 'prescriptive of how society should function, instead of the other way around'. Firstly, I don't think this point has been sufficiently developed in the paper, or at least it doesn't follow naturally from the arguments and examples given above. I am also concerned that because the author are buying into the revolutionary hype of genomic medicine, that society is construed as being essentially passive.

The point is to highlight the fact that different publics' views need to be taken in account as genomic technology becomes increasingly relevant in a range of settings. Whilst we would not want to construe the public as passive, we must not ignore the importance of power 
relationships and how in discourses of scientific and medical expertise 'non- expert' voices can be ignored. We believe that while it is important to value expertise, we must also ensure that there is dialogue and that non-expert voices do not become marginalised. This is why research into the attitudes and opinions of different publics is so valuable.

We would also point out that there are empirical examples of how new technologies can become prescriptive of the way society functions. This happens when what can be done is conflated with what should be done. For example, with prenatal screening programs, there is evidence that as new technologies become routinised they have driven medical practice. This happens when the 'normal' thing to do has became conflated with the 'right' thing to do. Scholars writing from a disabilities rights perspective have noted that this may subvert the wishes of patients who may not want screening. In a medical settings - where there are powerful power dynamics in play - patients may not feel empowered to state a preference that goes against what is 'normal' and 'right'. It is this we refer to when we say that technology may become prescriptive and we have added some text to further this argument on page 5, paragraph 2 of 'conclusions' section.

\section{Recommendations}

I recommend that the authors tone down their claims that genomic medicine is revolutionary and pervasive.

We hope we have managed to re-defend our view that genomics is indeed pervasive across society. We have, however, toned down our claims as requested.

I recommend the authors indicate that there are still significant obstacles of delivering personalised and stratified medicine in real-world settings.

We have added reference to the obstacles to delivering personalised medicine, however, we have not elaborated in detail on these as this wasn't the focus of the Opinion Piece and we wanted to keep the piece deliberately broad.

I recommend that the authors explore more deeply the kind of relationship individuals can expect from sequence-driven information, especially in relation to how this information is likely to change over time (see Joon-Hu et al. 2013¹).

We feel this could form a detailed discussion in a different paper (postulating on the possible futures that could exist with different applications of genomic medicine); however, Joon-Hu et al's theoretical debate about the relationship between person and their data, is not being applied in practice at the moment and thus we do not feel it should form a significant part of our current Opinion Piece.

\section{Minor revisions:}

On the last line of the second column on page 2 'where chemotherapies are targeted towards a people with...' should read 'where chemotherapies are targeted towards people with...'

\section{Corrected}


On page 3, first column, in the second paragraph $2^{\text {nd }}$ line provision of genetic counselling is of increasing in significance" should read "provision of genetic counselling is of increasing significance'.

Corrected

Competing Interests: No competing interests were disclosed.

Reviewer Report 06 December 2017

https://doi.org/10.5256/f1000research.13925.r28118

(C) 2017 Cowley L. This is an open access peer review report distributed under the terms of the Creative Commons Attribution License, which permits unrestricted use, distribution, and reproduction in any medium, provided the original work is properly cited.

\section{Lorraine Cowley}

Newcastle University, Newcastle upon Tyne, UK

The scope of this review does not include proof-reading; I have not commented on grammatical or typographical errors.

The authors have written a timely and relevant opinion piece which should be welcomed by the genetic counselling community. The article aims to explore how we might experience advancements in genomic technology as patients, consumers and citizens and urges policy makers to take stock of the human response to and pervasiveness of genomics. I strongly agree with the authors' conclusions that genomics is a current and important topic for society and in need of further psychosocial research. However, I would ask the authors to consider further illustrating and discussing the points made in the conclusion throughout the article.

As a general point, it would be helpful to have a brief statement about the academic disciplinary background of the authors to give the reader a better understanding about the context of the article and an idea about the lens through which their opinions are given.

Perhaps the potted history of the emergence of genomic technology in the abstract would sit better in the introduction with some comment from the authors on how the availability and reduced cost of technology is influencing its application. Some overstatement maybe avoided, for example, the countries they quote where genomic technology is being used outside the UK do not suggest global utilisation and maybe using alternative phrasing such as the 'economically developed world' would reflect the situation more accurately. As this is an opinion piece, it would have been good to see more critical engagement with the literature that the authors have cited and more of their opinion. Perhaps each quotation cited could be followed by comment from the authors; whether they contest, agree in part, find problematic or endorse what has been said. It would be helpful to have a brief explanation of their understanding of certain terms and concepts, 
as there are often inter and intra-disciplinary differences in definitions, for example, it would be helpful to know what their understanding is of 'normative bioethics'. It is welcome to see mention of the disability rights perspective and issues of potential discrimination with references to social science literature. Given that the opinion piece calls for a societal review, discusses sociological constructs such as citizenship and outlines current applications of genomic/genetic technologies, maybe it would be improved by further engagement with social science literature.

The authors aim to explore the human response to genetic advancements in genetics. A large proportion of the section headed 'People as patients' seems focused more on the technological capacity to offer tests and generate information rather than the human response to those technologies.

They make the point well about the shared nature of genetic information but stop short of acknowledging that not everyone has the same approach to knowing this information. The point could be enhanced by relating the discussion to the wealth of genetic counselling research that explores the communication of genetic risk in families, thus considering the implications for patients diagnosed with genetic conditions and those who do and do not want to know. I feel that this is a missed opportunity, if not to explore in detail, given the length of the article, at least to mention how finding out genetic information through mainstream diagnostic tests and/or direct to consumer (DTC) genetic testing may influence the communication dynamics within families about genetic risk and what this might mean to people. The authors seem to have assumed normativity in how genetic/genomic information is cascaded throughout families to 'patients in waiting' when in contemporary genetic counselling practice we know that this can be complex and challenging.

The article would be enhanced by either making explicit their stance towards the current and future applications of genomics which they have highlighted, or identifying authors who contest or problematize the issues. For example, but not limited to, it would be interesting to know their opinions on:

Do they uncritically accept that genomics poses responsibilities (Lucassen and Montgomery, 2017) for individuals and what do they understand those responsibilities to be?

What place do they think there is for dissenters or test decliners (if any) in the future genomic society?

What do they think about mainstreaming?

What do they think about the current and purported future use of DTC genetic testing or the issues this currently raises in genetic counselling?

What do they make of the claims about the usefulness of genetic information in, for example, the fitness industry?

Do they believe that people are equipped to make distinctions about the veracity of claims? Is there a contrasting point to be made in how clinicians interpret the clinical significance of (make distinctions about) genomic information and translate that into clinical care?

The authors flag the important idea that genomic testing may create uncertainty and this point could be enhanced by critically discussing the ways in which genomics dispels and confirms uncertainty and the limitations of what can be known versus what can be done.

Addressing these issues would go some way to exploring why policy-makers should approach the 
pervasiveness of genetics with caution. In summary, I believe the authors could state and argue more clearly the limitations to claims that genomics potentially benefits our health, our lifestyle and our cultural practices.

Given further critical engagement with these arguments, the opinion article could provide a strong overview of nascent genomics in the early twenty first century. This is a really useful article by leading and emerging researchers in the genetic counselling field and it would be beneficial to hear the authors' opinions more explicitly stated.

Is the topic of the opinion article discussed accurately in the context of the current literature?

Partly

Are all factual statements correct and adequately supported by citations?

Yes

Are arguments sufficiently supported by evidence from the published literature? Partly

Are the conclusions drawn balanced and justified on the basis of the presented arguments? Partly

Competing Interests: No competing interests were disclosed.

Reviewer Expertise: Genetic counselling, social science, bioethics

I confirm that I have read this submission and believe that I have an appropriate level of expertise to confirm that it is of an acceptable scientific standard, however I have significant reservations, as outlined above.

Author Response 18 Jan 2018

Jonathan Roberts, Connecting Science, Cambridge, UK

Thank you very much to Lorraine for her review. We have addressed her comments below (with reviewer comment in italics). As a broad response to the reviewer's comments we would thank her for thoughtful feedback. We accept that the reviewer draws attention a number of important debates. We would stress that the purpose of this article is to highlight, in a broad way, the myriad implications of genetics (and hence the need for continuing sociological research) without getting drawn into any specific ethical debates in detail.

The scope of this review does not include proof-reading; I have not commented on grammatical or typographical errors.

The authors have written a timely and relevant opinion piece which should be welcomed by the genetic counselling community. 
Thank you. While we hope the article will appeal to the genetic counselling community our main hope is that it will be read by a broad audience who may be interested in the future of genetics.

The article aims to explore how we might experience advancements in genomic technology as patients, consumers and citizens and urges policy makers to take stock of the human response to and pervasiveness of genomics. I strongly agree with the authors' conclusions that genomics is a current and important topic for society and in need of further psychosocial research. However, I would ask the authors to consider further illustrating and discussing the points made in the conclusion throughout the article.

As a general point, it would be helpful to have a brief statement about the academic disciplinary background of the authors to give the reader a better understanding about the context of the article and an idea about the lens through which their opinions are given.

I'm afraid we are restricted to the editorial policies of the journal and so unable to address this.

Perhaps the potted history of the emergence of genomic technology in the abstract would sit better in the introduction with some comment from the authors on how the availability and reduced cost of technology is influencing its application.

We feel this is covered in the opening paragraph and we believe that an extended history would not be warranted for a short opinion article.

Some overstatement maybe avoided, for example, the countries they quote where genomic technology is being used outside the UK do not suggest global utilisation and maybe using alternative phrasing such as the 'economically developed world' would reflect the situation more accurately.

We agree that it is important not to overstate the implementations of genetics. However, we feel it is important to stress that genomics is a global venture. Indeed the Global Alliance for Genomics and Health, representing 500+ organisations across the world, all involved in some way in the implementation of genomics, including in third world countries.

We have added some text to further clarify this on page 2, section "people as patients" paragraph 2.

As this is an opinion piece, it would have been good to see more critical engagement with the literature that the authors have cited and more of their opinion. Perhaps each quotation cited could be followed by comment from the authors; whether they contest, agree in part, find problematic or endorse what has been said. It would be helpful to have a brief explanation of their understanding of certain terms and concepts, as there are often inter and intra-disciplinary differences in definitions, for example, it would be helpful to know what their understanding is of 'normative bioethics'. It is welcome to see mention of the disability rights perspective and issues of potential discrimination with references to social science literature. Given that the opinion 
piece calls for a societal review, discusses sociological constructs such as citizenship and outlines current applications of genomic/genetic technologies, maybe it would be improved by further engagement with social science literature.

We welcome the comments regarding the need for a critical engagement with the literature. The aim and scope of this article was to provide an overview of the wide ranging implications of genomics and as such to draw attention to the need for ongoing research of the type that the reviewer mentions. The article is brief and written for a general audience therefore we do not feel we need to describe what our understanding of certain terminology, e.g. 'normative bioethics'.

The authors aim to explore the human response to genetic advancements in genetics. A large proportion of the section headed 'People as patients' seems focused more on the technological capacity to offer tests and generate information rather than the human response to those technologies.

We think the reviewer highlights important work, i.e. that which explores the human response to technologies. The aim of this paper was to provide a broad, accessible overview of the implications of genomics and as such to highlight the need for such sociological work. We feel that exploring in detail the sociological literature would be beyond the scope of this paper.

They make the point well about the shared nature of genetic information but stop short of acknowledging that not everyone has the same approach to knowing this information. The point could be enhanced by relating the discussion to the wealth of genetic counselling research that explores the communication of genetic risk in families, thus considering the implications for patients diagnosed with genetic conditions and those who do and do not want to know. I feel that this is a missed opportunity, if not to explore in detail, given the length of the article, at least to mention how finding out genetic information through mainstream diagnostic tests and/or direct to consumer (DTC) genetic testing may influence the communication dynamics within families about genetic risk and what this might mean to people. The authors seem to have assumed normativity in how genetic/genomic information is cascaded throughout families to 'patients in waiting' when in contemporary genetic counselling practice, we know that this can be complex and challenging.

\section{Possible new text:}

We think the reviewer raises an important point. This paper primarily focuses on the implications of technological advances and the need for ongoing sociological research. However, it is also important to note the rich vein of scholarship, especially that from genetic counselling, that explores the ways people understand and make sense of genetic information. We have added some text - page 3 column 2 paragraph 2 - to draw readers attention to this scholarship.

The article would be enhanced by either making explicit their stance towards the current and future applications of genomics which they have highlighted, or identifying authors who contest or problematize the issues. 
We appreciate the desire for a more explicit stance towards the applications of genomics. However we feel that to do this with such a broad overview of the topic has the potential to triple the length of the paper. As such we have not provided a thorough discussion about additional issues. This being said, the reviewer raises some important points and we have added some text to the paper that acknowledges the authors who have discussed problematic issues that have arisen regarding the implications of genetics. This can be found at page 3, column 1, paragraph 3

For example, but not limited to, it would be interesting to know their opinions on:

Do they uncritically accept that genomics poses responsibilities (Lucassen and Montgomery, 2017) for individuals and what do they understand those responsibilities to be?

Whether there are indeed responsibilities imposed by genomics and how these are handled by organisations, such as the NHS, could form the basis of a whole new paper and we do not feel we can do justice to this topic within the confines of a sentence or two.

What place do they think there is for dissenters or test decliners (if any) in the future genomic society?

We have added a sentence to draw readers attention to the important debate with respect dissenters or test decliners.page 3 column 2 paragraph 2, final line.

What do they think about mainstreaming?

Mainstreaming is such a large topic that it is difficult to summarise this within a sentence or two; we feel this is outside the scope of a broad overview piece. We have also published separately on the emerging roles for genetic counsellors in genomic medicine and the impact of mainstreaming, see Middleton et al

What do they think about the current and purported future use of DTC genetic testing or the issues this currently raises in genetic counselling?

We have separately published on this issue, see Middleton et al 2016

What do they make of the claims about the usefulness of genetic information in, for example, the fitness industry?

Do they believe that people are equipped to make distinctions about the veracity of claims? Is there a contrasting point to be made in how clinicians interpret the clinical significance of (make distinctions about) genomic information and translate that into clinical care?

These are all interesting and valid questions. The aim of the paper is to draw attention to the pertinence of these questions, to show the need for continuing research rather than to provide concrete answers or a comprehensive review of the sociological literature. The relationship between different publics, expertise and genetic information is the subject of the author's PhD and publications detailing this research will be forthcoming. 
The authors flag the important idea that genomic testing may create uncertainty and this point could be enhanced by critically discussing the ways in which genomics dispels and confirms uncertainty and the limitations of what can be known versus what can be done.

Research, especially from genetic counselling, has explored some of the complex ways that patients deal with uncertainty. The potential for increasing levels of uncertainty in genomics provides impetus for further research into how patients cope with, are resilient to and understand uncertainty. We have added some text at page 3 , column 1 , penultimate paragraph to draw readers attention to the complex debate surrounding uncertainty.

Addressing these issues would go some way to exploring why policy-makers should approach the pervasiveness of genetics with caution. In summary, I believe the authors could state and argue more clearly the limitations to claims that genomics potentially benefits our health, our lifestyle and our cultural practices.

The reviewer raises important points regarding the potential benefits and limitations of genetics. Within the confines of this short opinions piece we have added texts that further draws attention to this important debate.

Given further critical engagement with these arguments, the opinion article could provide a strong overview of nascent genomics in the early twenty first century. This is a really useful article by leading and emerging researchers in the genetic counselling field and it would be beneficial to hear the authors' opinions more explicitly stated.

Competing Interests: No competing interests were disclosed.

Reviewer Report 27 November 2017

https://doi.org/10.5256/f1000research.13925.r28114

(C) 2017 Michell A. This is an open access peer review report distributed under the terms of the Creative Commons Attribution License, which permits unrestricted use, distribution, and reproduction in any medium, provided the original work is properly cited.

\section{Anna Michell}

Division of Cardiovascular Medicine, Wellcome Trust Centre for Human Genetics, University of Oxford, John Radcliffe Hospital, Oxford, UK

The authors provide an overview of the current state of use of genomic technologies in the UK, comparing this with other nations as well as considering the wider implications of implementing such technologies for clinical practice and everyday life.

The use of association data by some companies or tests (rather than direct genomic data) is not dwelt upon in the section on DTC genetic testing although this is highlighted in the referenced 
literature. The distinction is one which is not always clear to the public and relates directly to the question posed at the end of this section about the lay person's genetic/genomic literacy and how well-equipped they are to evaluate such tests themselves.

Some consumers also use DTC testing from an Ancestry point of view and do not initially set out to learn medical genetic information from the test. However, tools which put related users in touch with each other can sometimes lead to disclosures of more medically-related information, such as recommendations about screening for inherited conditions.

The authors rightly highlight tensions between genomic data donated by patients to research endeavours on an altruistic basis and the possibility of a resultant financial benefit to organisations who provide capital, resources or facilities to support such endeavours. This is juxtaposed with the concomitant lack of value in being unable to share data for comparison and interpretation.

Finally, they draw attention to the great need for further research into the impact of these technologies on society as a whole - from a variety of perspectives - particularly focusing on the experiences of end-users, be they patients, consumers or citizens. Understanding the needs and concerns of these stakeholders is vital to successful delivery of services in the future.

Is the topic of the opinion article discussed accurately in the context of the current literature?

Yes

Are all factual statements correct and adequately supported by citations?

Yes

Are arguments sufficiently supported by evidence from the published literature?

Yes

Are the conclusions drawn balanced and justified on the basis of the presented arguments? Yes

Competing Interests: No competing interests were disclosed.

I confirm that I have read this submission and believe that I have an appropriate level of expertise to confirm that it is of an acceptable scientific standard. 
The benefits of publishing with F1000Research:

- Your article is published within days, with no editorial bias

- You can publish traditional articles, null/negative results, case reports, data notes and more

- The peer review process is transparent and collaborative

- Your article is indexed in PubMed after passing peer review

- Dedicated customer support at every stage

For pre-submission enquiries, contact research@f1000.com 